\title{
Apneic oxygen insufflation decreases the incidence of hypoxemia during one-lung ventilation in open and thoracoscopic pulmonary lobectomy: A randomized controlled trial
}

Dae Myung Jung, MD, ${ }^{a}$ Hyun Joo Ahn, MD, PhD, ${ }^{a}$ Sin-Ho Jung, $\mathrm{PhD},{ }^{\mathrm{b}}$ Mikyung Yang, MD, PhD, ${ }^{\mathrm{a}}$ Jie Ae Kim, MD, PhD, ${ }^{a}$ Su Min Shin, MD, ${ }^{c}$ and Suyong Jeon, $\mathrm{MD}^{\mathrm{a}}$

\section{ABSTRACT}

Objective: Hypoxemia is common during one-lung ventilation (OLV) for thoracic surgery. When hypoxemia occurs, surgery is interrupted for rescue ventilation. Apneic oxygen insufflation (AOI), which provides $\mathrm{O}_{2}$ without applying pressure, may prevent hypoxemia and does not interrupt surgery. The aim of this study was to determine the effectiveness of the AOI technique for preventing hypoxemia during OLV in thoracic surgery.

Methods: Patients undergoing open or thoracoscopic pulmonary lobectomy from September to December 2015 were included. Patients were assigned randomly to a non-AOI group or an AOI group $(n=45$ each). OLV was initiated and at the 15minute mark (OLV15), patients in the AOI group received oxygen insufflation at $3 \mathrm{~L} / \mathrm{min}$ to the nonventilated lung for 30 minutes (OLV45). The primary endpoint was the occurrence of hypoxemia $\left(\mathrm{SaO}_{2}<90 \%\right)$ during OLV.

Results: The demographic and operative data were similar between the 2 groups. The incidence of hypoxemia was greater in the non-AOI than the AOI group (18\% vs $0 \% ; P=.009$ ). $\Delta \mathrm{PaO}_{2}$ (the difference in partial pressure of oxygen in arterial blood between OLV 45 and 15 minutes) was smaller in the AOI than the non-AOI group ( $-29 \mathrm{~mm} \mathrm{Hg} \mathrm{vs}-69 \mathrm{~mm} \mathrm{Hg} ; P=.005)$. Duration of surgery and incidence of complications did not vary between groups.

Conclusions: AOI decreases the incidence of hypoxemia and improves arterial oxygenation during OLV for open and thoracoscopic surgery. AOI may be a valuable option to prevent hypoxemia. It can be used before relying on continuous positive airway pressure or intermittent two-lung ventilation and result in fewer interruptions in surgery. (J Thorac Cardiovasc Surg 2017;154:360-6)

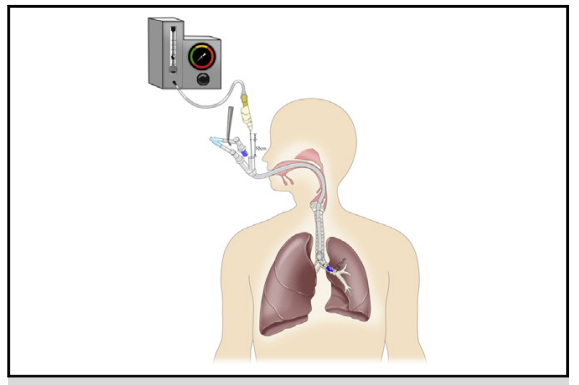

Apneic oxygen insufflation technique.

\section{Central Message}

Apneic oxygen insufflation can prevent hypoxemia during one-lung ventilation.

\section{Perspective}

Hypoxemia is common during one-lung ventilation for thoracic surgery. Apneic oxygen insufflation (AOI) can provide oxygen without applying pressure. We evaluated the effectiveness of the AOI technique for preventing hypoxemia without interruption of surgery during one-lung ventilation.

See Editorial Commentaries pages 367 and 369.
Hypoxemia, defined as a decrease in arterial oxygen saturation $\left(\mathrm{SaO}_{2}\right)<90 \%$, is not uncommon during one-lung ventilation (OLV), and the reported incidence is in the range of $1 \%$ to $24 \%$ in thoracic surgery. ${ }^{1-4}$ Because lifethreatening situations arise with hypoxemia, various

From the Departments of ${ }^{\mathrm{a}}$ Anesthesiology and Pain Medicine and ${ }^{\mathrm{c}}$ Thoracic and Cardiovascular Surgery, Samsung Medical Centre, Sungkyunkwan University School of Medicine; ${ }^{b}$ Biostatistics and Clinical Epidemiology Centre, Research Institute for Future Medicine, Samsung Medical Centre, Seoul, Korea.

Received for publication Aug 26, 2016; revisions received Feb 4, 2017; accepted for publication Feb 19, 2017; available ahead of print April 12, 2017.

Address for reprints: Hyun Joo Ahn, MD, PhD, Department of Anesthesiology and Pain Medicine, Samsung Medical Centre, 50, Irwon-dong, Gangnam-gu, Seoul 06351, Korea (E-mail: hyunjooahn@skku.edu).

0022-5223/\$36.00

Copyright (c) 2017 by The American Association for Thoracic Surgery

http://dx.doi.org/10.1016/j.jtcvs.2017.02.054 measures are taken to restore normoxia. ${ }^{5}$ While finding correctable causes such as double-lumen tube (DLT) malposition, attempts to reverse the ventilation/perfusion mismatch are tried.

To improve ventilation/perfusion mismatch, continuous positive airway pressure (CPAP) 5 to $10 \mathrm{~cm} \mathrm{H}_{2} \mathrm{O}$ is used before resorting to intermittent two-lung ventilation (TLV). ${ }^{6}$ Applying CPAP, however, requires interrupting surgery for a recruitment maneuver, and the subsequent

Scanning this QR code will take you to a supplemental video for the article. 


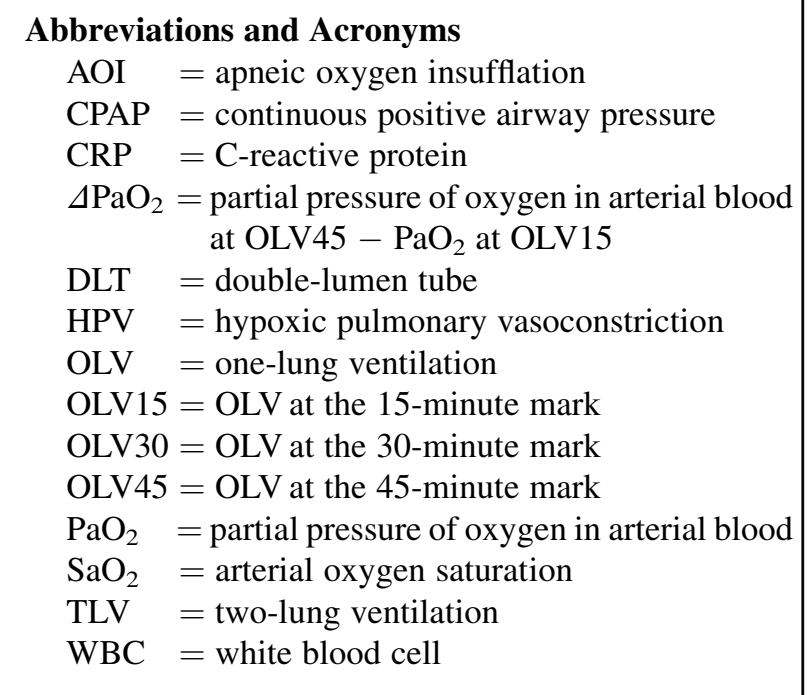

surgical view is impaired substantially. ${ }^{7}$ Although one report showed that a low level of CPAP is effective at reversing the hypoxemia and provides a good surgical field, the study was confined to open thoracic surgery. ${ }^{8}$

Intermittent positive pressure, ${ }^{9}$ selective segmental lung insufflations, ${ }^{10}$ and apneic oxygenation ${ }^{11-14}$ have been introduced as alternatives to CPAP; however, reports on these methods have limitations because they are preliminary studies, ${ }^{9-14}$ include a small number of cases, ${ }^{9-11}$ or are noncontrolled and nonrandomized trials. . $^{911,13,14}$ Therefore, to date, no generally accepted replacement or supplementary method for CPAP is available in hypoxic situations during OLV. Apneic oxygen insufflation (AOI) is to infuse $\mathrm{O}_{2}$ through an endotracheal tube without applying pressure. ${ }^{15}$ If $\mathrm{AOI}$ increases arterial oxygenation without interfering with surgery, it could help prevent hypoxemia and result in an adequate surgical environment during thoracic surgery.

Therefore, we conducted a randomized controlled trial of the AOI technique during OLV. We hypothesized that AOI technique would decrease the incidence of hypoxemia by $20 \%$ compared with the control technique in patients undergoing OLV for open or thoracoscopic pulmonary lobectomy.

\section{METHODS}

This prospective, randomized study was approved by the local institutional review board (SMC 2015-06-020) and registered with the Clinical Research Information Service (KCT0001629; principal investigator: Hyun Joo Ahn; date of registration: September 15, 2015). Written informed consent was obtained from all eligible patients before enrollment.

\section{Study Population}

Adult patients (aged $>19$ years) scheduled for elective open or thoracoscopic lobectomy in a single tertiary-care academic hospital were recruited. Exclusion criteria were American Society of Anesthesiologists physical status $>$ III and moderate degree lung disease by our institutional pulmonary function test guideline (either forced expiratory volume in $1 \mathrm{sec}$ ond/forced vital capacity $<60 \%$ and forced expiratory volume in 1 second $<50 \%$ or forced vital capacity $<50 \%$ ).

Patients with cardiac disease (history of angina, myocardial infarction, percutaneous coronary intervention, and coronary artery bypass graft), cerebrovascular disease (history of cerebral infarction, cerebral hemorrhage, and dementia), or liver disease (history of liver cirrhosis and hepatitis) were not excluded, and patients with pulmonary disease (chronic obstructive pulmonary disease, bronchiectasis, asthma, interstitial lung disease) but who did not meet the exclusion criteria were not excluded.

\section{Randomization and Blinding}

Consenting study participants were assigned randomly to 1 of 2 arms, a non-AOI group or an AOI group, by the use of computer-generated random numbers with a fixed block size of 4 on a 1:1 ratio. The investigator in charge of randomization wrote the patient's allocation on paper and sealed it in an opaque envelope. Experimental setup was completed before the induction of anesthesia. The principal investigator or coinvestigator opened the envelope to identify the assignment immediately before OLV initiation and turned the oxygen flow meter on or off according to group assignment. The flow meter was covered with an opaque cloth. Surgeon, patients, attending anesthesiologists, data recorder, and analyzer were blinded about group assignment.

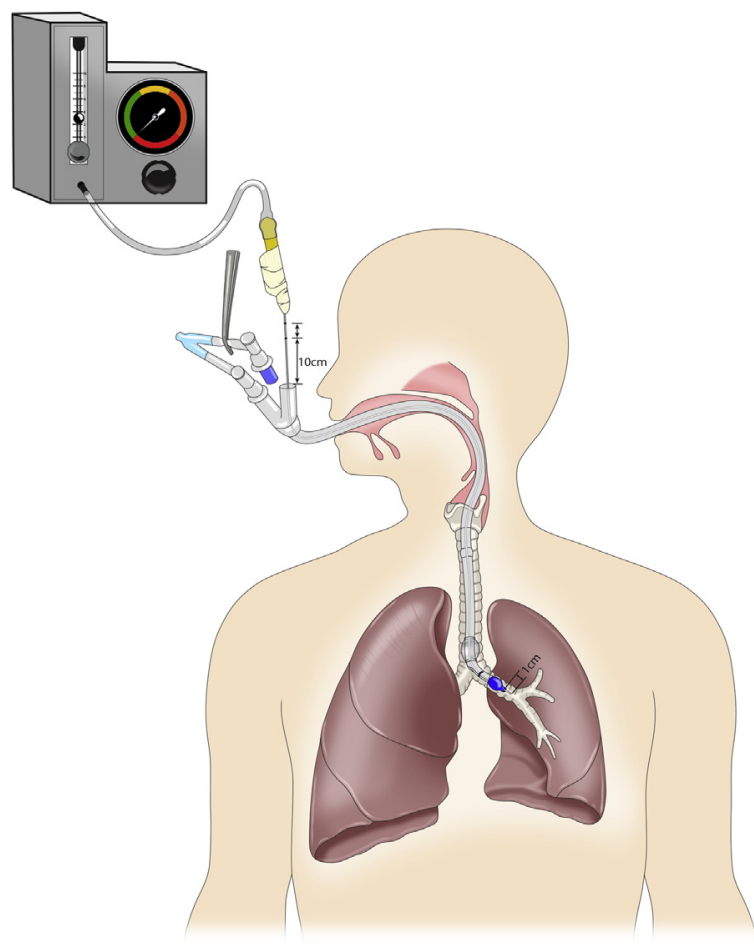

FIGURE 1. Apneic oxygen insufflation technique using endobronchial suction catheter and oxygen tubing. The suction catheter connected to oxygen flow meter was inserted into the non-ventilated side of the DLT. The lumen of DLT was open completely, and the catheter went through the full lumen of the tube as opposed to the smaller capped hole on DLT; thus, space between the suction catheter and the DLT lumen enabled free passage of gas. Insertion depth was predetermined and marked on the suction catheter before insertion. Predetermined depths were $1 \mathrm{~cm}$ beyond the opening of endobronchial lumen or $2 \mathrm{~cm}$ beyond the opening of endotracheal lumen, depending on the nonventilated side. 


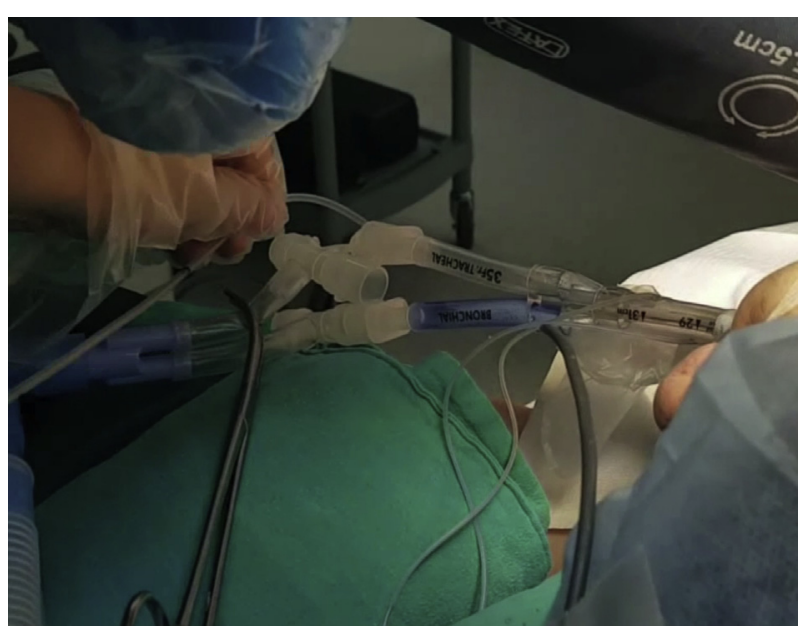

VIDEO 1. AOI technique. Video available at: http://www.jtcvsonline.org/ article/S0022-5223(17)30416-6/addons.

\section{Anesthesia and Monitoring}

All patients were monitored by 3-lead electrocardiogram, pulse oximetry, and noninvasive blood pressure before induction. Intubation was performed with a DLT (Broncho-Cath; Mallinckrodt Laboratories, Athlone, Ireland), and tube position was confirmed by fiberoptic bronchoscopy. An arterial catheter was placed in the radial artery opposite the surgical site. $\mathrm{SaO}_{2}$ was measured indirectly on the index finger by the use of an adhesive pulse oximeter (Oxisensor II; Covidien, Minneapolis, Minn). Tidal volume was set to a target of $8 \mathrm{~mL} / \mathrm{kg}$ predicted body weight during TLV and changed to $6 \mathrm{~mL} / \mathrm{kg}$ during OLV with $5 \mathrm{~cm} \mathrm{H}_{2} \mathrm{O}$ of positive endexpiratory pressure. Ventilation rate was adjusted to keep end-tidal carbon dioxide levels between 30 and $45 \mathrm{~mm} \mathrm{Hg}$. A 1.0 fraction of inspired oxygen was applied before OLV to facilitate lung collapse. ${ }^{16}$ After the beginning of OLV, fraction of inspired oxygen was decreased to 0.5 and maintained until the end of the study.

\section{Surgery}

Seven thoracic surgeons, who performed more than 140 major pulmonary resections per year, conducted operations and were unaware of group assignments. Lobectomies were performed through standard posterolateral thoracotomy or video-assisted thoracoscopic surgery as indicated. Vessels and bronchi of the target lobe were dissected individually. For patients with non-small cell lung cancer, a systematic lymph node dissection was mandatory.

\section{Study Protocol}

OLV was initiated and at the 15-minute mark (OLV15), and patients in the AOI group received oxygen insufflation at $3 \mathrm{~L} / \mathrm{min}$ to the nonventilated lung for 30 minutes (OLV45). Patients not receiving AOI were not supplied with oxygen but otherwise were prepared in the same manner as patients receiving AOI. When $\mathrm{SaO}_{2}$ decreased to less than $90 \%$, rescue maneuvers (CPAP or TLV) were started.

Arterial blood gas analysis was conducted shortly before the beginning of oxygen insufflation (OLV15) and at 15 minutes (OLV30) and $30 \mathrm{mi}-$ nutes (OLV45) into the study. Hemodynamic and ventilatory variables were recorded at 5 -minute intervals during the study period by a blinded recorder.

\section{AOI Technique}

We used a Mallinckrodt endobronchial suction catheter (10 Fr; Covidien) and oxygen tubing (7-ft Star Lumen Tubing; Hudson RCI, Morrisville, NC) for the AOI technique. One end of the oxygen tubing was connected to an independent oxygen flow meter of the ventilator, which was covered with an opaque cloth; the other end was connected to a suction

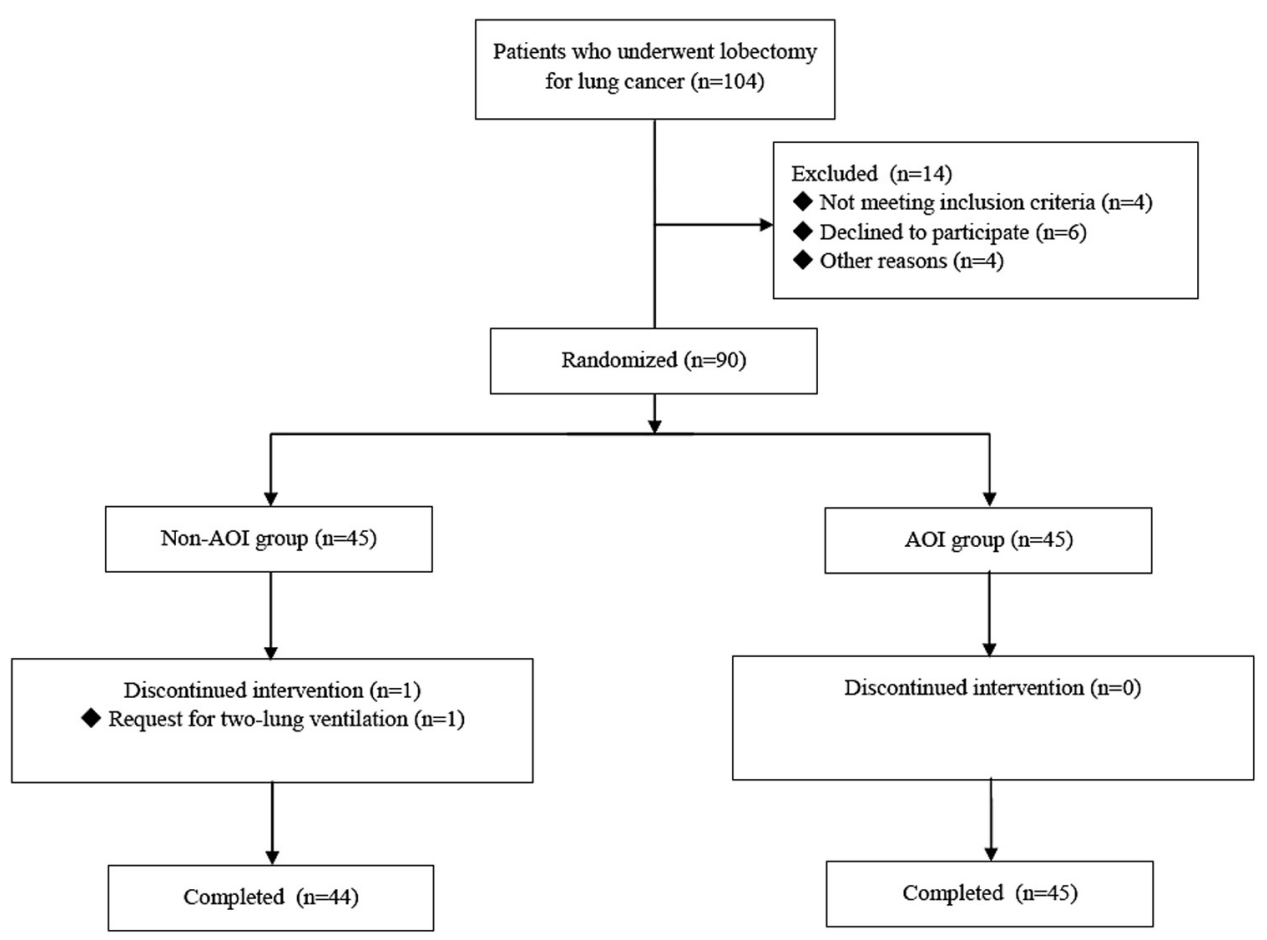

FIGURE 2. Consolidated Standards of Reporting Trials (CONSORT) flow diagram. AOI, Apneic oxygen insufflation. 
TABLE 1. Patient characteristics in non-AOI and AOI groups

\begin{tabular}{lccc}
\hline \multicolumn{1}{c}{ Variables } & $\begin{array}{c}\text { Non-AOI } \\
(\mathbf{n}=\mathbf{4 5})\end{array}$ & $\begin{array}{c}\text { AOI } \\
(\mathbf{n}=\mathbf{4 5})\end{array}$ & $\begin{array}{c}\boldsymbol{P} \\
\text { value }\end{array}$ \\
\hline Age, y & $62 \pm 10$ & $62 \pm 9$ & .9 \\
Male & $28(62)$ & $29(64)$ & .8 \\
BMI, kg/m ${ }^{2}$ & $24.4 \pm 2.4$ & $24.0 \pm 2.5$ & .4 \\
Current smoker & $10(22)$ & $6(13)$ & .3 \\
Preoperative lung injury* & $10(22)$ & $11(24)$ & .7 \\
Comorbidities & & & \\
$\quad$ Charlson comorbidity index & $4.2 \pm 1.4$ & $4.4 \pm 1.4$ & .7 \\
$\quad$ score & $19(42)$ & $16(36)$ & .5 \\
$\quad$ Hypertension & $11(24)$ & $7(16)$ & .3 \\
$\quad$ Diabetes & $2(4)$ & $3(7)$ & 1 \\
Angina/MI/CABG & $1(2)$ & $0(0)$ & 1 \\
$\quad$ Renal disease & $2(4)$ & $2(4)$ & 1 \\
Cerebral disease & $1(2)$ & $1(2)$ & 1 \\
$\quad$ Liver disease & $44(98)$ & $44(98)$ & 1 \\
Normal EKG & $2.7 \pm 0.7$ & $2.8 \pm 0.5$ & .6 \\
FEV1, L & $3.7 \pm 0.9$ & $3.7 \pm 0.7$ & .9 \\
DLCO, mL/mm Hg/min & $27(60) / 18(40)$ & $28(62) / 17(38)$ & .8 \\
Left/right surgery & $23(51) / 22(49)$ & $24(53) / 21(47)$ & .8 \\
VATS/open lobectomy &
\end{tabular}

Continuous variables are expressed as mean \pm standard deviation. Categorical variables are expressed in number (percentage). Group differences were compared by $\chi^{2}$ or Fisher exact tests for categorical variables and 2-sample $t$ tests for continuous variables. There were no differences between groups. AOI, Apneic oxygen insufflation; $B M I$, body mass index; $M I$, myocardial infarction; $C A B G$, coronary artery bypass graft surgery; $E K G$, electrocardiography; $F E V 1$, forced expiratory volume in 1 second; $D L C O$, diffusing capacity of the lung for carbon monoxide; VATS, videoassisted thoracoscopic surgery. *Preoperative lung injury includes chronic obstructive pulmonary disease, bronchiectasis, asthma, and interstitial lung disease.

catheter. The opening on the connector of the suction catheter was sealed with surgical silk plaster to prevent air leakage. The suction catheter was introduced into the nonventilated side of the DLT. The lumen of DLT was open completely, and the catheter went through the full lumen of the tube as opposed to the smaller capped hole on DLT; thus, space between the suction catheter and the DLT lumen enabled the free passage of gas. Insertion depth was predetermined and marked on the suction catheter before insertion. Predetermined depths were $1 \mathrm{~cm}$ beyond the opening of endobronchial lumen or $2 \mathrm{~cm}$ beyond the opening of endotracheal lumen, depending on the nonventilated side (Figure 1, Video 1).

\section{Outcomes}

The primary outcome was incidence of $\mathrm{SpO}_{2}<90 \%$. Secondary outcome was $\Delta \mathrm{PaO}_{2}$ (partial pressure of oxygen in arterial blood $\left[\mathrm{PaO}_{2}\right]$ at OLV45 $-\mathrm{PaO}_{2}$ at OLV15). Duration the operation, the incidence of postoperative complications and postoperative white blood cell (WBC) and C-reactive protein (CRP) also were recorded. Categories of postoperative complications were pulmonary, cardiovascular, urologic, neurologic, and wound problems.

\section{Statistical Analysis}

In a previous study, the incidence of $\mathrm{SpO}_{2}<90 \%$ was $24 \% .{ }^{4} \chi^{2}$ tests with a one-sided alpha of $5 \%$ for $20 \%$ decrease in incidence of hypoxemia required 80 patients for $80 \%$ power. Given up to $10 \%$ dropout or ineligibility, we planned to recruit 90 patients (45 each for the AOI and non-AOI groups).

$\chi^{2}$ or Fisher exact tests were used to compare categorical variables, and 2-sample $t$ tests were used to compare continuous variables. Durations of $\mathrm{SpO}_{2}$ less than $95 \%$ and $90 \%$ were compared by log-rank tests. Statistical analyses were performed with SAS (version 9.4; SAS Institute, Cary, NC)

\section{RESULTS}

A total of 104 patients were evaluated for eligibility between September and December 2015. Of these, 14 were excluded (4 did not meet inclusion criteria, 6 declined to participate, and 4 had a change in anesthetic or surgical procedure). Therefore, a total of 90 patients were assigned randomly to 1 of 2 groups: non-AOI $(n=45)$ or AOI $(n=45)$. In one patient in the non-AOI group, the surgeon asked for manual TLV to test air leakage before completing study; thus, this patient was excluded. As a result, 44 patients in the non-AOI group and 45 in the AOI group were analyzed for our primary endpoint (incidence of $\mathrm{SpO}_{2}<90 \%$ ) and for the analysis of operation
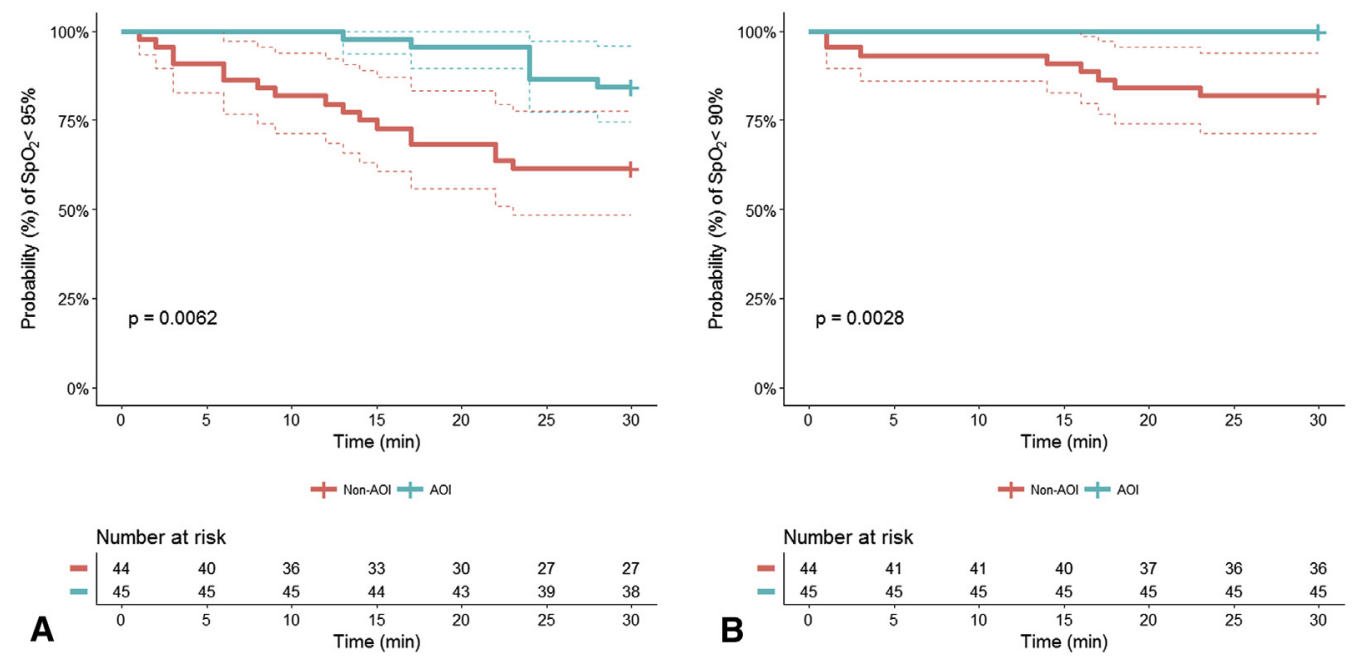

FIGURE 3. Probability of $\mathrm{SpO}_{2}$ (A) $<95 \%$ and (B) $<90 \%$ in non-AOI and AOI groups from 15 minutes to 45 minutes after OLV. Probability is depicted as Kaplan-Meier curves. $\mathrm{SpO}_{2}$, Oxygen saturation; AOI, apneic oxygen insufflation. Dotted lines are $95 \%$ the confidence limits. 
duration and postoperative complications. Our secondary outcome, $\Delta \mathrm{PaO}_{2}$ analysis, was conducted after we excluded patients who received rescue CPAP or TLV ( $\mathrm{n}=8$ in the non-AOI group, $\mathrm{n}=0$ in the AOI group) during the study period because this rescue maneuver increased $\mathrm{PaO}_{2}$. The CONSORT (Consolidated Standards of Reporting Trials) flow diagram of the study is shown in Figure 2. Baseline characteristics did not vary between groups (Table 1).

The incidence of $\mathrm{SpO}_{2}<95 \%$ was greater in the nonAOI group than the AOI group ( $39 \%$ vs $16 \% ; P=.015)$. The incidence of $\mathrm{SpO}_{2}<90 \%$ also was greater in the non-AOI group than the AOI group $(18 \%$ vs $0 \%$; $P=.009)$. The lowest $\mathrm{SpO}_{2}$ was greater in the AOI group than the non-AOI group (median $[95 \%$ confidence interval]: $97[96 \%-98 \%]$ and $96[94 \%-97 \%], P=.021)$. Time to $\mathrm{SaO}_{2}<95 \%$ and $\mathrm{SpO}_{2}<90 \%$ was longer in the AOI than the non-AOI group (Figure $3, A$ and $B$ ).

No difference was observed in baseline $\mathrm{PaO}_{2}$ (OLV15: $151 \pm 62 \mathrm{~mm} \mathrm{Hg}$ vs $154 \pm 52 \mathrm{~mm} \mathrm{Hg}$ in the non-AOI and AOI groups, $P=.8$ ); however, $\mathrm{PaO}_{2}$ was greater in the AOI group than the non-AOI group at all subsequent time points. Baseline $\mathrm{SpO}_{2}$ (OLV15) was not different between groups (98.4\% non-AOI vs $98.7 \%$ AOI; $P=.7$ ); however, $\mathrm{SpO}_{2}$ was greater in the AOI group than the non-AOI group at all subsequent time points (Figure 4).

Duration of operation was $153 \pm 62$ minutes and $131 \pm 44$ minutes in the non-AOI and AOI groups $(P=.5)$. The incidence of postoperative complications, postoperative $\mathrm{WBC}$, and postoperative CRP was not different between the non-AOI and AOI groups (Table 2).

\section{DISCUSSION}

Our study demonstrated that the AOI technique prevents hypoxemia during OLV in both open and video-assisted thoracoscopic surgery lobectomy. Frumin and colleagues ${ }^{15}$ first showed that apneic oxygenation maintained normal oxygen saturation for more than 45 minutes in humans by connecting an oxygen-filled circle apparatus to the endotracheal tube. The mechanism was aventilatory mass flow of oxygen, which enables the oxygen absorbed in alveoli to be replaced by passive oxygen movement through gas flow at ambient pressure. ${ }^{17}$ Apneic oxygenation has been used successfully in situations such as rigid bronchoscopy ${ }^{18}{ }^{18}$ endoscopy,${ }^{19}$ and endotracheal intubation. ${ }^{20}$ Unlike closed-chest and two-lung apneic oxygenation, however, the technique used in our study has been investigated rarely in open-chest and one-lung situations.

Pfitzner and colleagues ${ }^{21}$ stated that apneic oxygenation would not be useful in OLV because the lung is exposed to atmospheric pressure and collapses to the point of small airway closure. The same group, however, later found that a nonventilated lung collapses slowly and hypoxic pulmonary vasoconstriction (HPV) proceeds slowly when a lung
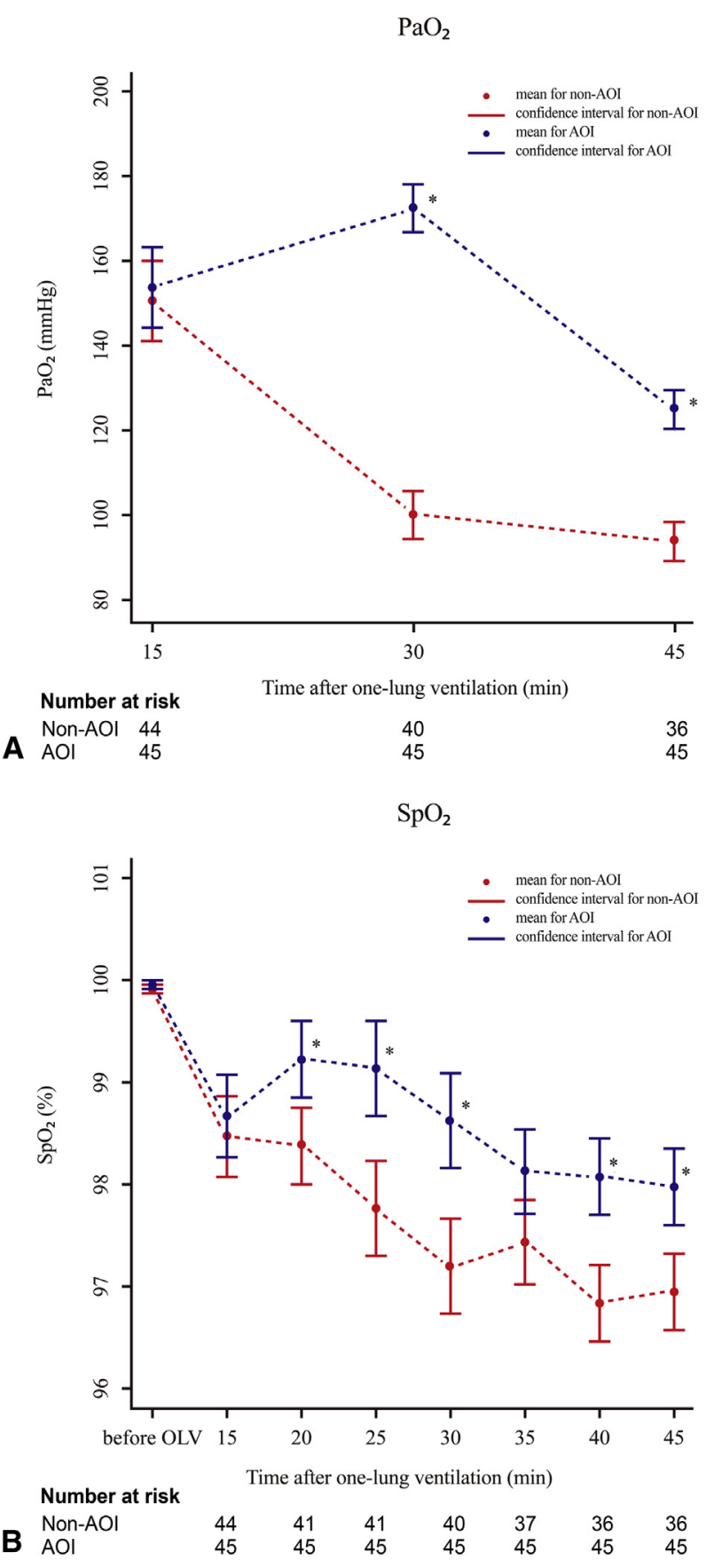

FIGURE 4. $\mathrm{A}, \mathrm{PaO}_{2}$ and $\mathrm{B}, \mathrm{SpO}_{2}$ in patients with or without $\mathrm{AOI}$ from 15 minutes to 45 minutes after OLV. $\mathrm{PaO}_{2}$, Partial pressure of oxygen in arterial blood; $\mathrm{AOI}$, apneic oxygen insufflation; $\mathrm{SpO}_{2}$, oxygen saturation; $O L V$, one-lung ventilation. $* P<.05$ between groups.

is insufflated with oxygen and reported that oxygen insufflation may be helpful in preventing hypoxia. ${ }^{22}$ Delay in both lung collapse and HPV progression by apneic oxygenation also is shown in animal experiments. ${ }^{23}$

Rees and Wansbrough ${ }^{12}$ showed that $\mathrm{AOI}$ increases $\mathrm{PaO}_{2}$ during OLV. This study enrolled only 12 patients in each the $\mathrm{AOI}$ and control groups and started $\mathrm{AOI}$ at the beginning of 
TABLE 2. Duration of operation and incidence of postoperative complications and postoperative $\mathrm{WBC}$ and $\mathrm{CRP}$

\begin{tabular}{lllc}
\hline \multicolumn{1}{c}{ Variables } & $\begin{array}{c}\text { Non-AOI } \\
(\mathbf{n}=\mathbf{4 5})\end{array}$ & \multicolumn{1}{c}{$\begin{array}{c}\text { AOI } \\
(\mathbf{n}=\mathbf{4 5})\end{array}$} & $\boldsymbol{P}$ value \\
\hline Duration of operation, $\min$ & $153 \pm 62$ & $131 \pm 44$ & .5 \\
Postoperative complications & $12(27)$ & $11(24)$ & .8 \\
Postoperative $\mathrm{WBC}, \times 10^{3} / \mu \mathrm{L}$ & $10.9 \pm 3.5$ & $12.3 \pm 3.0$ & .6 \\
Postoperative $\mathrm{CRP}, \mathrm{mg} / \mathrm{L}$ & $3.59 \pm 2.28$ & $4.02 \pm 2.64$ & .4 \\
\hline
\end{tabular}

Continuous variables are expressed as mean \pm standard deviation. Categorical variables are presented as number (percentage). $A O I$, Apneic oxygen insufflations; $W B C$, white blood cell; $C R P$, C-reactive protein

OLV. Decreasing the speed of lung collapse and delaying HPV by early application of AOI, however, are not desirable in most clinical OLV circumstances. Therefore, we tested whether AOI is effective when applied after lung collapse is established. In our study, the AOI technique was initiated 15 minutes after the beginning of OLV, so the nonventilated lung was adequately collapsed ${ }^{16}$ and HPV was functioning almost at full capacity. ${ }^{24}$ In addition, operations began approximately 15 minutes into OLV, resulting in further collapse of the nonventilated lung. Therefore, our results suggest that AOI is efficacious even when used after the lung is collapsed. This result indicates the usefulness of the AOI technique to prevent hypoxemia without the interruption of OLV during thoracic surgery.

The rate of insufflation in our study was $3 \mathrm{~L} / \mathrm{min}$. In closed-chest, two-lung apneic oxygenation, a gas flow greater than $0.3 \mathrm{~L} / \mathrm{kg} / \mathrm{min}$ is required for adequate $\mathrm{CO}_{2}$ removal. ${ }^{25}$ In an OLV situation, however, $\mathrm{CO}_{2}$ is removed by the ventilated lung. Thus, large gas flows to remove $\mathrm{CO}_{2}$ are not necessary. According to a study on selective segmental oxygen insufflation, an oxygen flow of $5 \mathrm{~L} / \mathrm{min}$ generated a pressure of $24 \mathrm{~cm} \mathrm{H}_{2} \mathrm{O}$, which is enough to reinflate collapsed alveoli. ${ }^{10}$ In our preliminary study, however, this flow rate was too high and overinflated the lung. Rees and Wansbrough ${ }^{12}$ provided oxygen at $1 \mathrm{~L} / \mathrm{min}$; however, this flow rate is too low to replace the outward movement of gas from the nonventilated lung and provide the alveoli with oxygen. Therefore, we chose a flow rate of $3 \mathrm{~L} / \mathrm{min}$, and it enabled appropriate oxygen delivery and did not impede the surgeon's view.

Catheter depth is another important issue in AOI. We used an animal study to decide depth. ${ }^{26}$ Deeper placement of the catheter tip can block the lobar bronchial orifice. In contrast, placement above the carina might result in insufficient gas turbulence for diffusion. ${ }^{27}$ Therefore, we considered $1 \mathrm{~cm}$ beyond the opening of the endobronchial lumen or $2 \mathrm{~cm}$ beyond the opening of the endotracheal lumen as an appropriate depth.

We saw no differences in duration of operation, incidence of postoperative complications, or postoperative serum WBC and CRP between the non-AOI and AOI groups. In an animal study, indicators of biochemical injury and cellular damage (malondialdehyde and myeloperoxidase) increased after bronchial occlusion and $\mathrm{OLV}^{28}$ In this regard, to retain oxygen flow via the AOI technique in the deflated lung may decrease ischemia-reperfusion injury. Our study is low powered for the analysis of complications. A larger scale study may reveal differences in biochemical and clinical outcomes between the groups.

This study has some limitations. First, it was performed for only 45 minutes during OLV. This period is considered to be when hypoxemia occurs most commonly. Nonetheless, AOI for longer periods during OLV would give us more information. In addition, studies applying AOI at various time points during OLV and applying AOI at the time when hypoxemia actually occurred would be necessary. Second, for safety reasons, we excluded patients with severe lung disease. A study design including patients vulnerable to OLV might have been more appropriate to the hypothesis of this study.

In conclusion, our study demonstrated that AOI decreases the incidence of hypoxemia and improves arterial oxygenation during OLV for open and thoracoscopic surgery. AOI may be a valuable option to prevent hypoxemia. It can be used before relying on CPAP or intermittent TLV, resulting in fewer interruptions in surgery.

\section{Conflict of Interest Statement}

Authors have nothing to disclose with regard to commercial support.

\section{References}

1. Karzai W, Schwarzkopf K. Hypoxemia during one-lung ventilation: prediction, prevention, and treatment. Anesthesiology. 2009;110:1402-11.

2. Brodsky JB, Lemmens HJ. Left double-lumen tubes: clinical experience with 1,170 patients. J Cardiothorac Vasc Anesth. 2003;17:289-98.

3. Toolabi K, Aminian A, Javid MJ, Mirsharifi R, Rabani A. Minimal access mediastinal surgery: one or two lung ventilation? J Minim Access Surg. 2009;5:103-7.

4. Ehrenfeld JM, Mulvoy W, Sandberg WS. Performance comparison of right- and left-sided double-lumen tubes among infrequent users. J Cardiothorac Vasc Anesth. 2010;24:598-601.

5. Rozé H, Lafargue M, Ouattara A. Case scenario: management of intraoperative hypoxemia during one-lung ventilation. Anesthesiology. 2011;114:167-74.

6. Benumof JL. One-lung ventilation: which lung should be PEEPed? Anesthesiology. 1982;56:161-3.

7. Bailey J, Mikhail M, Haddy S, Thangathurai D. Problems with CPAP during onelung ventilation in thoracoscopic surgery. J Cardiothorac Vasc Anesth. 1998;12: 239.

8. Hogue Charles W Jr. Effectiveness of low levels of nonventilated lung continuous positive airway pressure in improving arterial oxygenation during one-lung ventilation. Anesth Analg. 1994;79:364-7.

9. Russel WJ. Intermittent positive airway pressure to manage hypoxia during onelung anesthesia. Anaesth Intensive Care. 2009;37:432-4.

10. Ku CM, Slinger P, Waddell TK. A novel method of treating hypoxemia during one-lung ventilation for thoracoscopic surgery. J Cardiothorac Vasc Anesth. 2009;23:850-2.

11. Sanchez-Lorente D, Gomez-Caro A, Jimenez MJ, Molins L. Apnoeic oxygenation on one-lung ventilation in functionally impaired patients during sleeve lobectomy. Eur J Cardiothorac Surg. 2011;39:e77-9.

12. Rees DI, Wansbrough SR. One-lung anesthesia: percent shunt and arterial oxygen tension during continuous insufflation of oxygen to the nonventilated lung. Anesth Analg. 1982;61:507-12.

13. Capan LM, Turndorf H, Patel C, Ramanathan S, Acinapura A, Chalon J. Optimization of arterial oxygenation during one-lung anesthesia. Anesth Analg. 1980 59:847-51. 
14. Pfitzner J, Peacock MJ, Daniels BW. Ambient pressure oxygen reservoir apparatus for use during one-lung anaesthesia. Anaesthesia. 1999;54:454-8.

15. Frumin MJ, Epstein RM, Cohen G. Apneic oxygenation in man. Anesthesiology. 1959;20:789-98.

16. Ko R, McRae K, Darling G, Waddell TK, McGlade D, Cheung K, et al. The use of air in the inspired gas mixture during two-lung ventilation delays lung collapse during one-lung ventilation. Anesth Analg. 2009;108:1092-6.

17. Bartlett RG Jr, Brubach HF, Specht H. Demonstration of aventilatory mass flow during ventilation and apnea in man. J Appl Physiol. 1959; 14:97-101.

18. Pathak V, Welsby I, Mahmood K, Wahidi M, MacIntyre N, Shofer S. Ventilation and anesthetic approaches for rigid bronchoscopy. Ann Am Thorac Soc. 2014;11: 628-34.

19. Rudlof B, Hohenhorst W. Use of apneic oxygenation for the performance of panendoscopy. Otolaryngol Head Neck Surg. 2013;149:235-9.

20. Semler MW, Janz DR, Lentz RJ, Matthews DT, Norman BC, Assad TR, et al. Randomized trial of apneic oxygenation during endotracheal intubation of the critically Ill. Am J Respir Crit Care Med. 2016;193:273-80.

21. Pfitzner J, Peacock MJ, Daniels BW. Administering ambient pressure oxygenation to the non-ventilated lung during thoracoscopic surgery. Anaesthesia. 2001; $56: 281-2$.
22. Pfitzner J, Pfitzner L. The theoretical basis for using apnoeic oxygenation via the non-ventilated lung during one-lung ventilation to delay the onset of arterial hypoxaemia. Anaesth Intensive Care. 2005;33:794-800.

23. Cannon D, Kalso EJ, Sykes MK. Effects of the pattern of ventilation and of an increase in cardiac output on the distribution of blood flow to a hypoxic lung lobe. Br J Anaesth. 1988;60:81-90.

24. Moudgil R, Michelakis ED, Archer SL. Hypoxic pulmonary vasoconstriction. J Appl Physiol (1985). 2005;98:390-403.

25. Mackenzie CF, Barnas GM, Smalley J, Moorman R, Baptiste J. Low-flow endobronchial insufflation with air for 2 hours of apnea provides ventilation adequate for survival. Anesth Analg. 1990;71:279-84.

26. Slutsky AS, Menon AS. Catheter position and blood gases during constant-flow ventilation. J Appl Physiol (1985). 1987;62:513-9.

27. Cook TM, Wolf AR, Henderson AJ. Changes in blood-gas tensions during apnoeic oxygenation in paediatric patients. Br J Anaesth. 1998;81:338-42.

28. Tekinbas C, Ulusoy H, Yulug E, Erol MM, Alver A, Yenilmez E, et al. One-lung ventilation: For how long? J Thorac Cardiovasc Surg. 2007;134:405-10.

Key Words: apneic oxygenation, hypoxemia, one-lung ventilation 